\title{
EXPERIMENTAL STAPHYLOCOCCAL INFECTIONS IN NEWBORN MICE: INHIBITION OF WEIGHT GAIN AS AN INDEX OF VIRULENCE
}

\author{
Oonagh S. Kinsman* and J. P. ArbuthnotT \\ Department of Microbiology, The Moyne Institute, University of Dublin, \\ Trinity College, Dublin 2
}

MANY ATTEMPTS have been made to set up experimental models to study staphylococcal infections. Often the route of challenge determines the disease produced. Mastitis results from inoculation into the mammary glands of mice and rabbits (Chandler, 1970; Adlam et al., 1976), osteomyelitis from injection into the bone marrow of rabbits (Norden, 1970), and endocarditis from intravenous injection in rabbits and rats (Nickerson et al,. 1969; Santoro and Levison, 1978). In respect of subcutaneous infection, except for a few important studies of experimental infection in man (Elek and Conen, 1957; Maibach, 1965; Marples and Kligman, 1976), most work has been performed on mice. As in most other experimental models of staphylococcal infection, large challenge doses are needed to produce subcutaneous lesions in adult mice, though these can be avoided if the organisms are injected with plugs of cotton dust (Noble, 1965). To assess the virulence of strains of staphylococci in terms of mortality, LD50 measurements have been made after intraperitoneal injections in mice (Chesbro, Wamola and Bartley, 1969), intracerebral injections in newborn mice (Namavar et al., 1976 and 1978) and intra-allantoic injections in chick embryos (McCabe, 1964).

Recently, McKay and Arbuthnott (1979) showed that newborn mice are more susceptible than adult mice to subcutaneous challenge with staphylococci and compared the virulence of strains by assessing mortality and lesion formation. We have now made a more detailed investigation of this mouse model in an attempt to devise criteria other than mortality for assessing the virulence of staphylococci.

\section{MATERIALS AND METHODS}

Bacterial strains. We studied 13 isolates of staphylococci (table I). These included six clinical isolates of Staphylococcus aureus from various infections, four multiple-antibiotic-resistant isolates of $S$. aureus from a study of hospital cross infection, two isolates of $S$. epidermidis and the reference "mouse-virulent" strain of S. aureus no. PS80 (NCTC9789).

Mouse strain. The Sha Sha strain of mouse was used; this is homozygous from the gene "shaven". The mice never grow a first coat of hair and the adults have only a few short hairs. This "hairless" strain was chosen to study subcutaneous infection because it eliminated the necessity Diseases of the Skin, Homerton Grove, London E9 6BX. 
TABLE I.

Origin of strains of staphylococci used

\begin{tabular}{|c|c|}
\hline $\begin{array}{c}\text { Strain } \\
\text { no. }\end{array}$ & Origin \\
\hline $\begin{array}{l}\text { SM10* } \\
\text { SM9* } \\
\text { SM6* } \\
908 \dagger \\
909 \dagger \\
1205 \dagger \\
1692 \dagger \\
584{ }^{\dagger} \\
503 \dagger \\
571 \dagger \\
506 \dagger \\
\text { ML549† } \\
\text { PS80(NCTC 9789) }\end{array}$ & 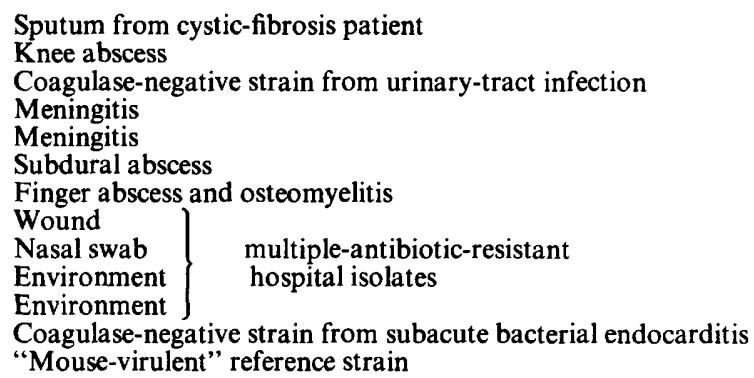 \\
\hline
\end{tabular}

* Strains isolated in 1972-1974 in Glasgow (McKay and Arbuthnott, 1979).

† Strains isolated in Dublin hospitals during 1976.

for shaving in older animals. Pregnant females were checked daily for the production of litters to ensure that the age of neonates was known accurately. Individual 3-day-old mice were weighed, and those weighing $1.4 \mathrm{~g}-2.4 \mathrm{~g}$ were used. The average weight at 3 days was $1.9 \mathrm{~g}$ (standard deviation 0.2). Adult animals were not less than 8 weeks old. In weight-gain experiments, 3-day-old mice were colour-coded to allow individual animals to be weighed at different time intervals. Entire litters were challenged and returned to their mothers. Inoculated controls were similarly treated. Handling treatment during challenge did not result in cannibalism or rejection.

Culture and maintenance of bacterial strains. Standard suspensions of thrice-washed cells were prepared as described by McKay and Arbuthnott (1979).

Challenge procedure. Cell suspensions $(0.05-\mathrm{ml}$ volumes) were injected subcutaneously along the dorsal midline of newborn and adult animals.

Assessment of growth of organisms in the skin. At time intervals after challenge, animals were individually weighed and then killed, and the skin around the site of infection was removed. This was $c .1 \mathrm{~cm}^{2}$ in area in newborn animals and $c .2 \mathrm{~cm}^{2}$ in adult mice. The skin was homogenised in $10 \mathrm{ml}$ of cold phosphate-buffered saline, $p \mathrm{H} \mathrm{7 \cdot 0}$, in 10-ml glass tissue-grinders (Jencons Scientific Ltd, Herts). Surface viable counts of the homogenates were made on Mannitol Salt Agar (Oxoid) and the results expressed as colony-forming units (c.f.u.) in the whole preparation. The skin count at each time point was taken as the mean of counts from five adult mice or between five and 15 newborn mice.

Assessment of percentage weight gain. A minimum of 30 3-day-old animals were given subcutaneous injections of peptone water, the suspending medium for the test organisms, and the weight of each animal was measured at daily intervals. Weight gain for individual animals was calculated and expressed as a percentage of the respective initial weights. Mean values were calculated for groups of animals at different times. Percentage weight gain was assessed in the same way for experimentally infected animals. With virulent staphylococcal strains tested at high challenge doses, some deaths occurred; this emphasised the need to follow the weight of individual animals in the course of the experiment as opposed to average litter weights. Test values were compared statistically to control values by means of Student's $t$-test.

\section{RESULTS}

\section{Experimental infection in adult and newborn mice}

The difference in the response of adult and newborn mice to staphylococcal 


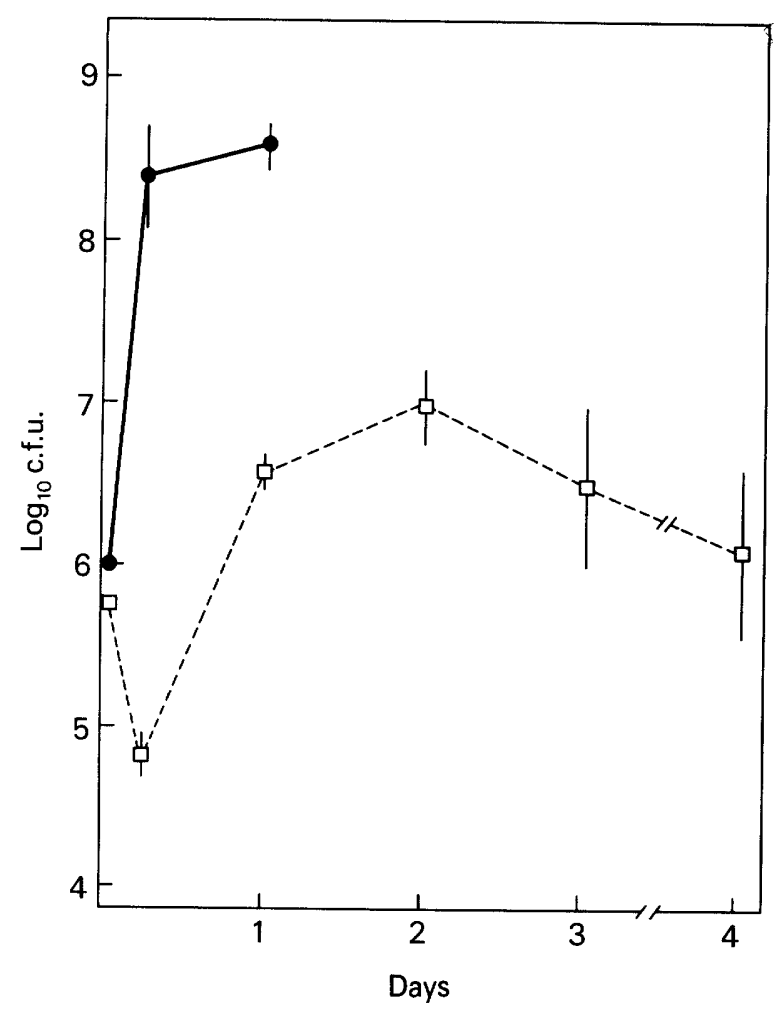

FIG. 1. Growth of Staphylococcus aureus strain SM10 in the skin of 3-day-old and adult mice with an inoculum of $10^{7}$ colony-forming units (c.f.u.): $\bullet=3$-day old; $\boldsymbol{\square} \cdots$ - $=$ adult.

infection can be seen in fig. 1. With an inoculum of $10^{7}$ c.f.u. of strain SM10, multiplication occurred to a much greater extent in newborn than in adult animals. Mortality rates among newborn animals at this challenge dose were such that sampling could not take place after 1 day and lesions in surviving animals were extensive. No deaths occurred in adult animals and lesions were barely detectable. Analysis of data on mortality of newborn mice at 5 days after challenge with varying doses $\left(10^{7}, 10^{6}, 10^{5}\right.$ c.f.u $)$ revealed that susceptibility to infection depended on the weight of animals at the time of challenge (table II). Mortality rates after challenge with $10^{5}$ and $10^{6}$ c.f.u. were highest in the group having the lowest initial weigh range, while at a challenge dose of $10^{7}$ c.f.u. there was a $100 \%$ mortality in all three weight groups. Because mortality rates in newborn mice were affected by the weight of the animals at the time of challenge, we examined alternative indices of virulence.

\section{Assessment of body weight in relation to skin counts in newborn mice}

The mean skin counts at times up to 5 days after challenge with $10^{6} \mathrm{c}$.f.u. of strain SM10 are shown in fig. 2. There was a rapid increase in the number of organisms recovered from surviving mice after the first $24 \mathrm{~h}$. Skin bacterial 


\section{TABLE II.}

Effect of initial weight on percentage mortality of 3-day-old mice* 5 days after challenge with Staphylococcus aureus strain SM10

\begin{tabular}{c|ccc}
\hline $\begin{array}{c}\text { Challenge dose: } \\
\text { colony-forming } \\
\text { units (c.f.u) }\end{array}$ & \multicolumn{4}{|c}{ Percentage mortality $\dagger$ of animals, at the time of challenge weighing (g) } \\
\cline { 2 - 4 } & $\begin{array}{c}1 \cdot 4-1 \cdot 8 \\
\text { A }\end{array}$ & $\begin{array}{c}1 \cdot 9-2 \cdot 1 \\
\text { B }\end{array}$ & C \\
\hline $10^{5}$ & 21 & 0 & 0 \\
$10^{6}$ & 88 & 55 & 46 \\
$10^{7}$ & 100 & 100 & 100 \\
\hline
\end{tabular}

* A minimum of 30 animals were used per challenge dose.

† There is no significant difference $(p>0.05)$ at any challenge dose between values in column $B$ and $C$. However, with the exception of the challenge dose of $10^{7}$ c.f.u., the values in columns $B$ and $C$ are each significantly different from those in column $A(p<0 \cdot 01)$.

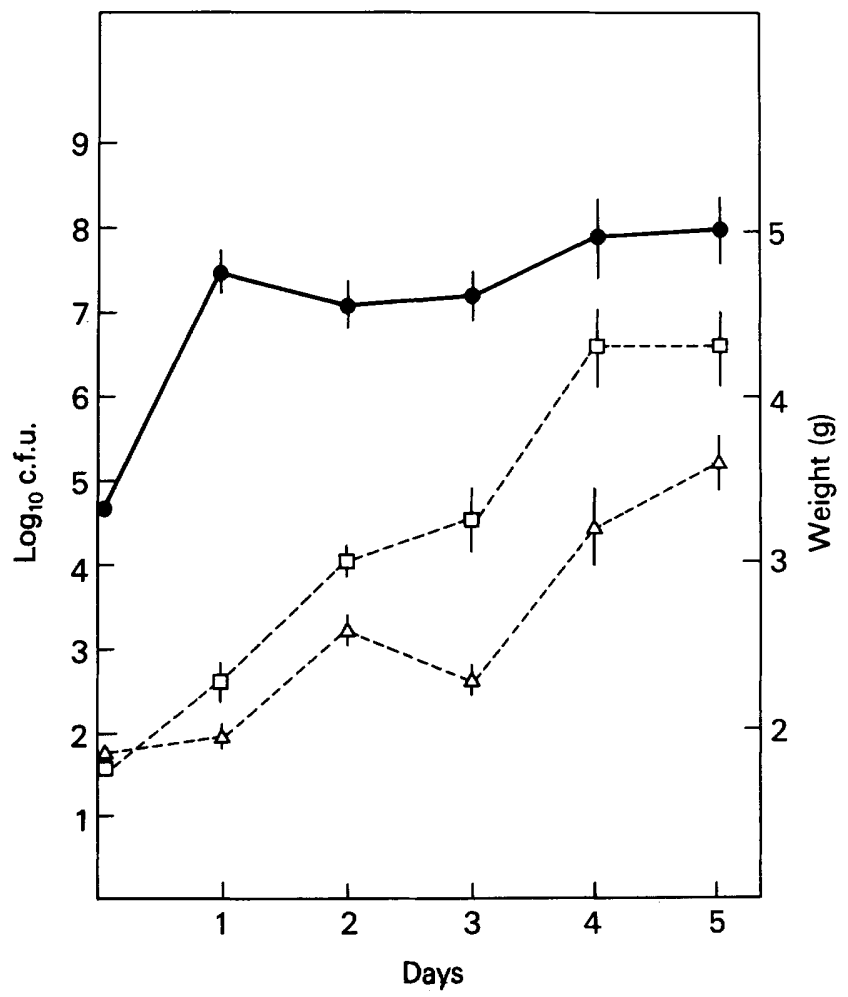

FIG 2-Growth of S. aureus strain SM10 in the skin of 3-day-old mice with an inoculum of $10^{6}$ organisms, and weights of animals with skin counts above and below the mean: $\bullet-$ skin counts; $\square$. . a average weight of animals with counts below the mean; $\Delta \cdots \Delta$ average weight of animals with counts above the mean. 
counts and the weights of surviving individual animals were noted at the time of sampling. The average weights of animals with skin counts greater than, and with skin counts less than the mean are also shown in fig. 2. This revealed that the heavier animals on average had the lower skin counts.

A further set of experiments showed a correlation between the percentage weight gain after challenge and the rate of multiplication of organisms in the skin. The coagulase-negative strain SM6 was compared with S. aureus strain SM10 (fig. 3). In one experiment, multiplication of the organisms in the skin was studied (fig. 3b); skin counts of strain SM6 decreased over the period studied while those of strain SM10 increased, especially during the first $24 \mathrm{~h}$. In a parallel experiment, the ability of surviving animals to gain weight was determined (fig. $3 a$ ). The percentage weight gain of control animals injected with peptone water increased in a nearly linear fashion. However, in animals given strain SM10, which multiplied rapidly in the skin, the percentage weight gain was much reduced in the first 2 days in comparison with the control,

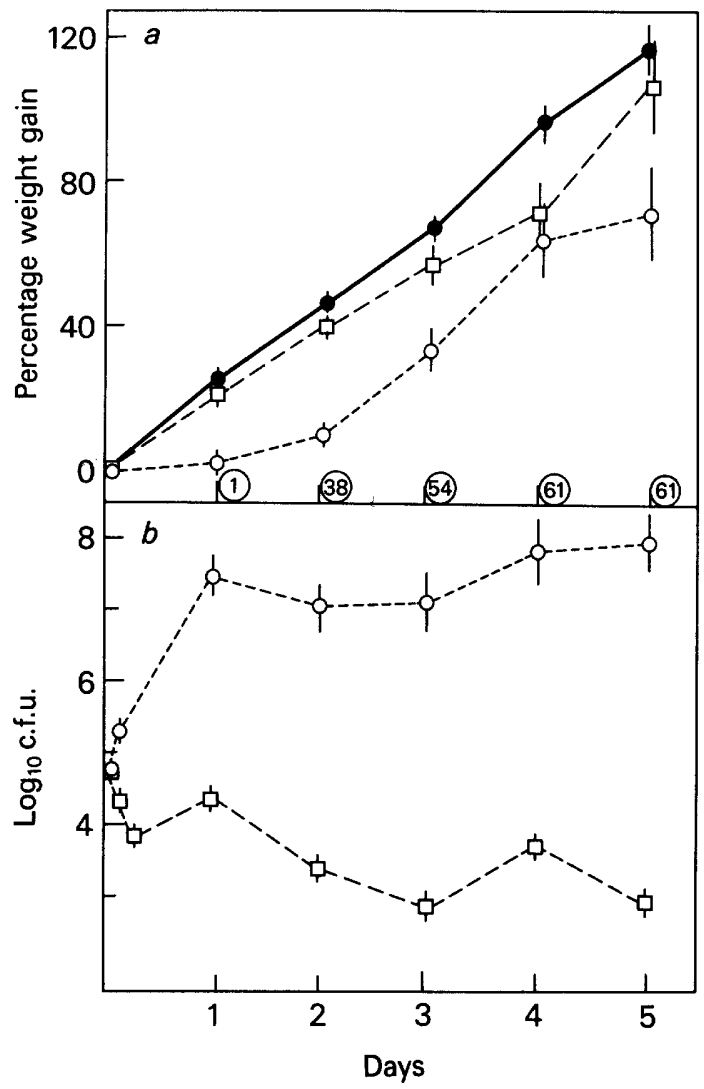

FIG 3.-a. Percentage weight gain of 3-day-old mice inoculated with $10^{6}$ c.f.u. of $S$. aureus strain SM10 or $S$. epidermidis strain SM6: $-\quad-$ control; $\circ \cdots 0=$ SM 10; $\square-\cdots=$ SM6; encircled figures = cumulative percentage mortality for strain SM10. b. Growth from similar inocula of $S$. aureus strain SM10 and $S$. epidermidis strain SM6 in the skin: $0 \cdots \circ=$ SM10; $\square---\square=$ SM6. 


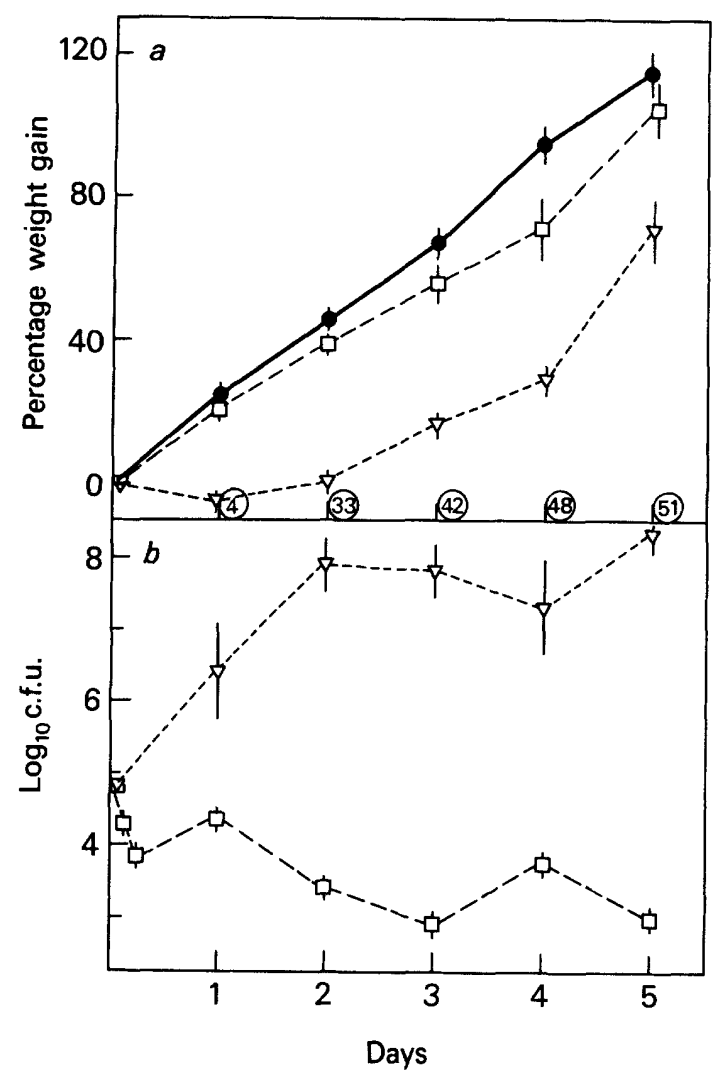

FIGURE 4. - $a$. Percentage weight gain of 3-day-old mice inoculated with $10^{6}$ c.f.u. of S. aureus strain SM9 or S. epidermidis strain SM6: $\bullet=$ control; $\nabla \cdots \nabla=$ SM9; $\square---\square=$ SM6; encircled figures $=$ cumulative percentage mortality for strain SM9. b. Growth from similar inocula of $S$. aureus strain SM9 and $S$. epidermidis strain SM6 in the skin: $\nabla \cdots \nabla=$ SM9; $\cdots \cdots=$ SM6.

whereas the pattern of weight gain for strain SM6, which showed no net multiplication in the skin, was similar to that for control. Experiments with another mouse-virulent strain SM9 (fig. 4) again showed a marked reduction in normal weight gain for 2 days after challenge. A feature worthy of note was that the inhibition of normal weight gain with both strains was most evident in the first 2 days and was less apparent thereafter. Within 1 or 2 days after challenge with the two mouse-virulent strains there was rapid multiplication in the skin and an almost complete cessation of normal weight gain. Between days 2 and 3 there appeared to be a critical point after which the surviving animals, despite the presence of high skin counts, began to gain weight to some extent. It is interesting to note that the cumulative mortality rates (given as encircled values in figs. 3 and 4) also levelled out between days 3 and 4.

From these findings it appeared likely that weight gain could be used to assess the severity of infection in the early stages. Accordingly more detailed weight-gain studies were performed with the coagulase-negative strain SM6 and the coagulase-positive strains SM9 and SM10 at different challenge doses. 
TABLE III

Percentage weight gain of 3-day-old infected mice at 1 day after challenge

\begin{tabular}{l|ccc}
\hline $\begin{array}{c}\text { Staphylococcal } \\
\text { strain } \\
\text { no. }\end{array}$ & \multicolumn{4}{|c}{ Percentage weight gain at challenge dose (c.f.u.) of } \\
\cline { 2 - 3 } & $10^{5}$ & $10^{6}$ & $10^{7}$ \\
\hline SM6 & $17 \cdot 8$ & $21 \cdot 2$ & $19 \cdot 4$ \\
SM9 & $7 \cdot 0^{*}$ & $-4 \cdot 9^{*}$ & $-2 \cdot 5^{*}$ \\
SM10 & $17 \cdot 9$ & $1 \cdot 4^{*}$ & $0 \cdot 5^{*}$ \\
Control group & $\ldots$ & $23 \cdot 1$ & $\ldots$ \\
\hline
\end{tabular}

* Significantly different from the control $(\mathrm{p}<0.05)$.

The results at 1 day and 2 days after challenge are shown in tables III and IV. Strain SM9 had a significant inhibitory effect on weight gain with a challenge dose of $10^{5}$ c.f.u., and this and strain SM10 had an even more marked effect with higher doses. However, with a challenge of $10^{7}$ c.f.u., mortality rates for strains SM9 and SM10 were high at 2 days; as a result, meaningful values for weight gain could not be obtained at this time. At no stage were the results for strain SM6 significantly different from the control.

\section{Weight gain as an index of virulence}

The above results indicated that inhibition of normal weight gain was related to the severity of experimental infection. Accordingly, we compared a range of clinical isolates using percentage weight gain at 2 days after challenge with $10^{6} \mathrm{c}$.f.u. as an index of virulence. Two days was selected as the time point for measurement of weight gain on the basis of results of skin counts and weight gain in earlier experiments. The results for 13 strains including SM6, SM9 and SM10 are shown in table V. Strains could be arranged according to their effect in inhibiting weight gain; the greatest effect was observed with strains that were known or expected to be virulent. Strains of low virulence included the coagulase-negative isolates and multiple-antibiotic-resistant $S$. aureus strains. The latter strains were from a study of aminoglycoside-resistant isolates and were resistant to several other antibiotics. All strains gave results significantly different from the control $(p<0 \cdot 01)$ except SM6 $(p>0 \cdot 1)$.

TABLE IV

Percentage weight gain of 3-day-old infected mice at 2 days after challenge .

\begin{tabular}{l|ccc}
\hline $\begin{array}{c}\text { Staphylococcal } \\
\text { strain } \\
\text { no. }\end{array}$ & \multicolumn{3}{|c}{ Percentage weight gain at challenge dose (c.f.u.) } \\
\cline { 2 - 4 } \multicolumn{1}{c}{} & $10^{5}$ & $10^{6}$ & $10^{7}$ \\
\hline SM6 & $36 \cdot 2$ & $39 \cdot 0$ & $37 \cdot 8$ \\
SM9 & $21 \cdot 5^{*}$ & $0 \cdot 7^{*}$ & $\ldots$ \\
SM10 & $38 \cdot 0$ & $9 \cdot 1^{*}$ & $\ldots$ \\
Control group & $\ldots$ & $45 \cdot 8$ & $\ldots$ \\
\hline
\end{tabular}

* Significantly different from the control $(\mathrm{p}<0 \cdot 05)$. 
TABLE V

Comparison of the virulence of 13 clinical isolates of staphylococci by measurement of the percentage weight gain of newborn mice at 2 days after subcutaneous challenge with $10^{6}$ c.f.u.

\begin{tabular}{l|cl}
\hline $\begin{array}{c}\text { Strain } \\
\text { no. }\end{array}$ & $\begin{array}{c}\text { Percentage weight gain } \\
\text { ( } \pm \text { s.e.) }\end{array}$ & \multicolumn{1}{c}{$\begin{array}{c}\text { Source } \\
\text { (and clinical assessment*) }\end{array}$} \\
\hline SM9 & $0 \cdot 1 \pm 2 \cdot 7$ & Abscess \\
908 & $0 \cdot 4 \pm 2 \cdot 5$ & Meningitis (4) \\
1208 & $6 \cdot 6 \pm 3 \cdot 2$ & Abscess \\
909 & $9 \cdot 1 \pm 2 \cdot 1$ & Meningitis (4) \\
SM10 & $9 \cdot 1 \pm 3 \cdot 9$ & Sputum (4) \\
1692 & $17 \cdot 8 \pm 3 \cdot 4$ & Abscess (4) \\
PS80 & $18 \cdot 1 \pm 3 \cdot 3$ & "Mouse-virulent" reference strain \\
584 & $19 \cdot 3 \pm 6 \cdot 2$ & Wound (2) \\
571 & $27 \cdot 5 \pm 3 \cdot 7$ & Environmental isolate (2) \\
ML549† & $29 \cdot 0 \pm 2 \cdot 9$ & Subacute bacterial endocarditis \\
503 & $33 \cdot 0 \pm 3 \cdot 3$ & Nasal swab (2) \\
506 & $36 \cdot 4 \pm 3 \cdot 0$ & Environmental isolate (2) \\
SM6† & $39 \cdot 0 \pm 3 \cdot 9$ & Urinary-tract infection \\
\hline Control group & $45 \cdot 2 \pm 3.9$ & \\
\hline
\end{tabular}

\footnotetext{
* The most recent isolates from Dublin hospitals were supplied with an accompanying assessment of the severity of infection on a scale from mild (1) to serious (4).

† Coagulase-negative strains.
}

In the experiments described here, control mice were in litters separated from infected animals, but recent studies suggest that it is possible to use alternate animals in a litter as controls with little risk of cross infection. Such a procedure reduced variability between litters.

\section{Discussion}

The findings reported here confirm the observations of McKay and Arbuthnott (1979) that newborn mice are more susceptible than adult animals to experimental staphylococcal infection by the subcutaneous route. They also show that, after subcutaneous injection, a coagulase-positive strain (SM10) multiplies to a much greater extent in neonatal than in adult skin. The reason for this difference in susceptibility is not known, but may be the immunological immaturity of newborn mice, as suggested by Namavar et al. (1978) as a result of their studies of intracerebral challenge with coagulasenegative staphylococci.

In a series of base-line studies, several criteria were assessed as indices of the severity of infection and virulence of the test organism. An analysis of mortality rates revealed that the weight of animals at the time of challenge determined to a certain extent the mortality rate. When skin counts were made in surviving mice, a high skin count was correlated with a low body weight at the time of sampling. This suggested that it would be instructive to study weight changes in the course of infection; it was then found that two clinical isolates of known mouse virulence, strains SM9 and SM10 (McKay and Arbuthnott, 1979), caused marked inhibition of normal weight gain. An 
almost complete inhibition of weight gain occurred in the first 2 days after challenge, during which time both mouse-pathogenic strains multiplied rapidly in the skin. After this critical period, surviving animals began to gain weight, but the retardation of weight gain remained evident within the period of study ( 5 days). The marked inhibition of weight gain in the first 2 days may reflect a systemic response to the rapid multiplication of these mouse-virulent strains. No such effect was seen with the coagulase negative-strain SM6, which failed to multiply in the skin. The mechanisms responsible for the inhibition of weight gain are not known. However it is important to note that, as reported earlier (McKay and Arbuthnott, 1979), strains SM9 and SM10 differ markedly in toxinogenicity; SM10 was a highly $\alpha$-toxinogenic strain whereas SM9 was non-toxinogenic. Whether or not the mice survive infection may reflect differences in the degree of immunological maturity of individual mice of the same age. This would be consistent with the differences in mortality rate observed in experiments in which 3-day-old animals were grouped according to weight (table II).

In subsequent experiments in which a number of staphylococcal strains were tested, it was found that these strains could be graded according to their effect on weight gain 2 days after challenge; impairment of normal weight gain was most obvious with strains previously shown to be highly virulent for newborn mice, e.g., SM9 and SM10 (see McKay and Arbuthnott, 1979), and others considered to have caused severe lesions in human patients. Several of these caused greater impairment of weight gain than did the standard strain PS80, rated as "mouse virulent" on the grounds of its ability to cause subcutaneous lesions when injected along with a plug of cotton dust.

It is well known from clinical experience that the susceptibility of patients to staphylococcal infection depends on host factors as well as the virulence of the organism. However in studies of epidemiology and pathogenic mechanisms there is a need for rapid tests of staphylococcal virulence. The general pattern of our results suggests that inhibition of weight gain in neonatal mice may be a useful criterion of virulence for the highly susceptible subject. The test is easy to perform, and is more discerning than measurement of mortality and less tedious than estimation of skin counts in newborn mice.

We are at present engaged in studies with this model to assess the relative virulence of mutants of $S$. aureus deficient in haemolysin and coagulase production, and of strains of coagulase-negative staphylococci.

\section{SUMMARY}

We attempted to evaluate the neonatal mouse model as an indicator of the virulence of staphylococcal strains freshly isolated from human patients in hospital. In preliminary studies with two previously characterised clinical isolates of Staphylococcus aureus and one of S. epidermidis, three indices of infection were studied. These were: mortality rate, multiplication of organisms in the skin, and the effect on weight gain. Of these, inhibition of normal weight gain by mice given subcutaneous injections when 3 days old was the most 
convenient and easily applied test. At a challenge dose of $10^{6}$ c.f.u., the multiplication of organisms in the skin was correlated with the inhibition of normal weight gain. Weight gain was used to compare the virulence of a small series of clinical isolates from different types of staphylococcal infection. Strains isolated from severe infections caused a greater inhibition of weight gain than did strains from milder infections or environmental sources.

We thank Professor C. T. Keane, Central Microbiology Laboratory, Adelaide Hospital, Dublin, for providing some of the clinical isolates and giving us a clinical assessment of severity of infection, and for much stimulating discussion.

\section{REFERENCES}

Adlam, C., Thorley, C. M., Ward, P. D., Collins, M., Lucken, R. N. ANd Knight, P. A. 1976. Natural and experimental staphylococcal mastitis in rabbits. J. comp. Path., 86, 581.

Chandler, R. L. 1970. Experimental bacterial mastitis in the mouse. J. med. Microbiol., 3, 273.

Chesbro, W. R., Wamola, I. AND Bartley, C. H. 1969. Correlation of virulence with growth rate in Staphylococcus aureus. Can. J. Microbiol. 15, 723.

ELEK, S. D. AND CONEN, P. E. 1957. The virulence of Staphylococcus pyogenes for man. Br. J. exp. Path., 38, 573.

MCCABE, W. R. 1964. Studies of staphylococcal infections. I. Virulence of staphylococci and characteristics of infections in embryonated eggs. J. clin. Invest., 43, 2146.

McKaY, S. A. AND ARbuthnotT, J. P. 1979. Age related susceptibility of mice to staphylococcal infection. J. med. Microbiol., 12,99.

MaIBACH, H. I. 1965. Experimentally induced infections in the skin of man. In Skin bacteria and their role in infection, edited by H. I. Maibach and G. Hildick-Smith. McGraw-Hill: New York, p. 85.

MarPles, R. R. AND Kligman, A. M. 1976. Experimental staphylococcal infections of the skin in man. In Staphylococci and staphylococcal diseases, edited by J. Jeljaszewicz, Gustav Fischer Verlag: Stuttgart. p. 755.

NAMAVAR, F., DE GRAaFF, J. AND VeRhoEF, J. 1976. Virulence of staphylococci (with special reference to experimental infection in neonatal mice, and phagocytosis by polymorphonuclear cells). Zentbl. Bakt. ParasitKde, I Abt. Orig., A, suppl. 5, 813.

Namavar, F., DE GraAfF, J., DE WITH, C. AND Maclaren, D.M. 1978. Novobiocin resistance and virulence of strains of Staphylococcus saprophyticus isolated from urine and skin. $J$. med. Microbiol., 11, 243.

Nickerson, D. S., Kazmierowski, J. A., Dossett, J. H., Williams, R. C. and Quie, P. G. 1969. Studies of immune and normal opsonins during experimental staphylococcal infection in rabbits. J. Immun., 102, 1235.

NoBLE, W. C., 1965. The production of subcutaneous staphylococcal skin lesions in mice. $B r$. J. exp. Path., 46, 254.

NoRDEN, C.W., 1970. Experimental osteomyelitis. I. A description of the model. J. infect. Dis., 122, 410.

SANTORO, J. AND Levison, M.E. 1978. Rat model of experimental endocarditis. Infect. Immun., 19, 915. 